\title{
Hfq-dependent regulation of OmpA synthesis is mediated by an antisense RNA
}

\author{
Klas I. Udekwu, ${ }^{1}$ Fabien Darfeuille, ${ }^{1}$ Jörg Vogel, ${ }^{2}$ Johan Reimegård, ${ }^{1}$ Erik Holmqvist, ${ }^{1}$ and \\ E. Gerhart H. Wagner ${ }^{1,3}$ \\ ${ }^{1}$ Department of Cell and Molecular Biology, Uppsala University, S-75124 Uppsala, Sweden; ${ }^{2}$ Max Planck Institute for \\ Infection Biology, D-10117 Berlin, Germany
}

This paper shows that the small RNA MicA (previously SraD) is an antisense regulator of ompA in Escherichia coli. MicA accumulates upon entry into stationary phase and down-regulates the level of ompA mRNA. Regulation of ompA (outer membrane protein A), previously attributed to Hfq/mRNA binding, is lost upon deletion of the micA gene, whereas overexpression of MicA inhibits the synthesis of OmpA. In vitro, MicA binds to the ompA mRNA leader. Enzymatic and chemical probing was used to map the structures of MicA, the ompA mRNA leader, and the complex formed upon binding. MicA binding generates a footprint across the ompA Shine-Dalgarno sequence, consistent with a $12+4$ base-pair interaction, which is additionally supported by the effect of mutations in vivo and by bioinformatics analysis of enterobacterial micA/ompA homolog sequences. MicA is conserved in many enterobacteria, as is its ompA target site. In vitro toeprinting confirmed that binding of MicA specifically interferes with ribosome binding. We propose that MicA, when present at high levels, blocks ribosome binding at the ompA translation start site, which-in line with previous work-secondarily facilitates RNase E cleavage and subsequent mRNA decay. MicA requires the presence of the Hfq protein, although the mechanistic basis for this remains unclear.

[Keywords: Antisense RNA; Hfq; OmpA; regulatory RNA; translational control]

Supplemental material is available at http://www.genesdev.org.

Received June 3, 2005; revised version accepted August 2, 2005.

Genome-wide searches conducted in recent years have uncovered $\sim 70$ small RNAs (sRNAs) encoded by the chromosome of the enterobacterium Escherichia coli alone (Argaman et al. 2001; Rivas et al. 2001; Wassarman et al. 2001; Chen et al. 2002; Vogel et al. 2003; Zhang et al. 2003). Homologs are often found in close relatives, and additional sRNAs have been identified in several other bacteria. No biological functions have yet been assigned to the vast majority of $E$. coli sRNAs. The functionally characterized sRNAs mostly appear to be involved in stress responses; many of them are induced under specific stress conditions and control target mRNAs in order to promote the adaptive changes required to cope with adverse conditions (Wagner and Vogel 2003; Gottesman 2004). Examples are OxyS (oxidative stress), IstR (SOS response), DsrA (cold shock), RyhB (iron stress), and MicF (osmotic stress). Expression patterns suggest that many sRNAs are candidates for regulators of transitions into stationary phase (Argaman et al. 2001; Wassarman et al. 2001; Vogel et al. 2003).

${ }^{3}$ Corresponding author.

E-MAIL gerhart.wagner@icm.uu.se; FAX 46-18-530396.

Article and publication are at http://www.genesdev.org/cgi/doi/10.1101/ gad.354405.
Of the sRNAs characterized so far, most act by antisense mechanisms, that is, regulate via base-pairing to a target mRNA, whereas only a few sRNAs act by protein sequestration (e.g., CsrB, CsrC, 6S RNA) (Wagner and Vogel 2003; Gottesman 2004; Storz et al. 2004). Antisense RNAs can be activators or-more frequently-inhibitors of target RNA function. A strikingly versatile example is provided by RNAIII, the key regulator of virulence in Staphyloccocus aureus, which is encoded by the agr locus. This RNA uses different structural domains to act as (1) an mRNA for hemolysin a, (2) an activator antisense RNA for up-regulation of hld (encoding hemolysin d), and (3) an antisense RNA that down-regulates spa (encoding the adhesin protein A) (Morfeldt et al. 1995; Huntzinger et al. 2005). Even in E. coli, multiple targets for single sRNAs are known; for example, DsrA regulates both hns (HN-S transcriptional regulator) and rpoS (Stationary phase/General stress Sigma factor; $\sigma^{\mathrm{s}}$ ). The converse situation has also been found: Three different sRNAs-OxyS, DsrA, and RprA-all converge on rpoS for regulation (Repoila et al. 2003).

A major player in the regulatory activity of many chromosomally encoded sRNAs is the Sm-like protein Hfq (Valentin-Hansen et al. 2004). It is present at high con- 
centration in $E$. coli cells $(\approx 10 \mu \mathrm{M} / \approx 10,000$ hexamers per cell in logarithmic growth) (Kajitani et al. 1994; Ali Azam et al. 1999). Hfq binds many sRNAs (and target RNAs) (e.g., Zhang et al. 2003; Geissmann and Touati 2004; Mikulecky et al. 2004) with high affinities and is often required for their regulatory activity (Wagner and Vogel 2003; Gottesman 2004; Storz et al. 2004). The reason for the Hfq requirement is still enigmatic, but different mechanisms have been proposed (see Discussion). Most antisense RNAs from bacterial chromosomes are trans-encoded; antisense and target genes do not overlap. Consequently, antisense/target RNA complementarity is incomplete, and the complexes formed comprise limited base-paired stretches including noncanonical base pairs, often interrupted by internal bulges/loops (Wagner and Vogel 2003). In contrast, almost all antisense RNAs of plasmids, transposons, and phages are cis-encoded (the same DNA segment encodes both RNAs in opposite orientation) and thus fully complementary to their respective target RNAs (Wagner et al. 2002). In the cases tested, these antisense RNAs are Hfq-independent for regulation (J.G. Slagter-Jäger and E.G.H. Wagner, unpubl.).

Interestingly, Hfq is also required for regulation of the ompA gene. OmpA is one of the major outer membrane proteins in E. coli and many related bacteria. OmpA synthesis is growth-rate-controlled (Lugtenberg et al. 1976), and regulation of $\mathrm{ompA}$ mRNA stability has been reported (Nilsson et al. 1984; Vytvytska et al. 1998, 2000). In addition, this unusually stable mRNA has featured prominently in studies aimed at relationships between secondary structure motifs, translatability, and RNA half-life (Belasco et al. 1986; Arnold et al. 1998). In this paper, we revisited ompA regulation. During the functional characterization of a new E. coli sRNA, SraD, discovered in a previous screen (Argaman et al. 2001), we identified $\operatorname{omp} A$ as the post-transcriptionally regulated target. SraD is here renamed to MicA, in keeping with MicF and MicC, two unrelated sRNAs, that regulateby an antisense mechanism-their respective targets, the $o m p F$ and ompC (outer membrane proteins/porins) mRNAs (Andersen et al. 1989; Chen et al. 2004). The data presented reinterpret earlier reports about Hfq-dependent regulation of $o m p A$ by showing that regulation is exerted by the MicA antisense RNA, which, in turn, requires functional $\mathrm{Hfq}$ protein. In vitro analysis indi- cates that inhibition of $\operatorname{ompA}$ gene expression is achieved by the binding of MicA to the translation initiation region (TIR) of ompA mRNA, thus preventing ribosome binding.

\section{Results}

\section{MicA overexpression results in decreased OmpA protein levels}

The micA gene is clockwise oriented in the E. coli K12 MG1655 genome, and is located in the intergenic region between the counterclockwise-oriented luxS and gsh $A$ genes (Fig. 1A). Homologs of micA are present in many enterobacteria (Supplementary Tables S1, S2). Previous work had shown that MicA increased in abundance upon entry into stationary phase (Argaman et al. 2001). The 5' and $3^{\prime}$-ends of MicA were mapped by primer extension analysis (5'-end) (data not shown) and RACE (5' - and $3{ }^{\prime}$ ends) (Argaman et al. 2001), and are indicated in Figure 1B. Early attempts to identify a biological role for micA involved physiological tests conducted on wild-type and $\Delta$ micA isogenic E. coli strains but failed to give significant phenotypes under a variety of conditions.

We therefore resorted to proteome analysis to identify putative regulatory targets. Since the micA gene lies in the short luxS-gshA intergenic region, its deletion might affect the neighboring genes. To avoid possible secondary effects, a wild-type E. coli strain was supplied with either one of three high-copy plasmids so that high, normal, or very low intracellular levels of MicA could be obtained. Constitutive high levels of MicA were provided from pMicA. Negligible MicA levels were obtained by out-titration of endogenous MicA by plasmid pAntiMicA (see also Fig. 4, below); micA and anti-micA sequences, inserted downstream of a Lambda $\mathrm{P}_{\mathrm{L}}$ promoter, are shown in Figure 1 (see Materials and Methods for details). The third plasmid, pControl, carried a promoterless lacZ fragment and was used as a control; in the presence of this plasmid, normal endogenous MicA levels are present. Two-dimensional polyacrylamide gel electrophoresis (2D-PAGE) was carried out on total protein extracted from plasmid-containing strains. Normalized spot intensity values enabled the identification of candidates for differential expression, and spots differing
Figure 1. The micA locus. (A) The location of the micA gene (counterclockwise orientation) in the luxS-gshA intergenic region is indicated. DNA sequences inserted to obtain pMicA and pAnti-MicA, respectively, are shown. The black arrows indicate the orientation of the inserts in the vector, downstream of the promoter. The insert in pAnti-MicA is followed by an $\operatorname{rrn} B$ terminator, such that the transcript has a length of $\approx 90 \mathrm{nt}$. (B) Sequence of the DNA specifying MicA (bold) with putative promoter elements indicated. The MicA-encoding sequence is shown in bold, and the +1 position, as determined by primer extension and RACE analyses, is indicated. Lines above the DNA sequence indicate the two halves of the stem of the MicA terminator.
A

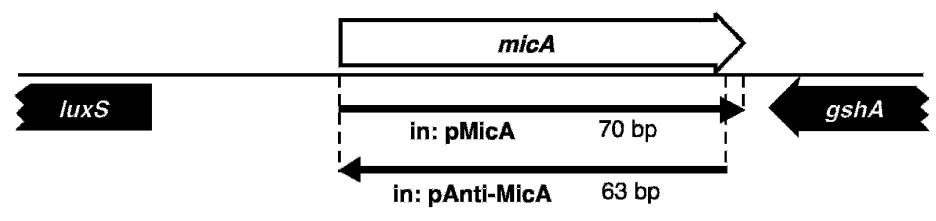

$\mathbf{B}$

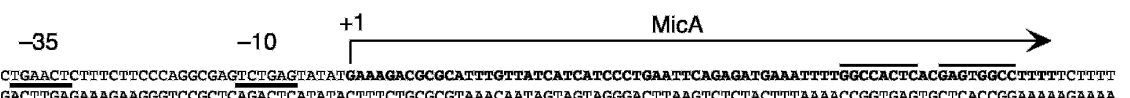

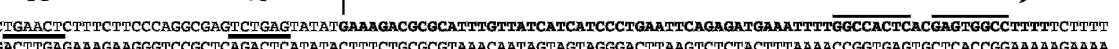


by more than a factor of 2.5 from one strain-plasmid combination to another were identified by MALDI-TOF mass spectrometry and subsequent peptide peak analysis. Of the candidates, OmpA showed the greatest deviation from control samples: MicA overexpression decreased OmpA protein levels by $\approx 10$-fold (Fig. 2A). Thus, the ompA gene is directly or indirectly regulated by MicA.

\section{Conservation analysis of MicA and its putative target region in ompA $m R N A$}

In parallel, we used a new target search algorithm to identify putative targets of MicA RNA. This program (to be described in detail elsewhere; J. Reimegård and E.G.H. Wagner, in prep.) searched, in this case, for regions of MicA complementarity in sequence windows containing the translation initiation regions (TIRs) of all annotated E. coli ORFs. The algorithm permits noncontiguous pairing and noncanonical base pairs. Subsequently, the antisense/target RNA candidate list is compared to reiterated searches in closely related bacteria, and higher scores are given for conservation of putative base-pairing between species. Conducting this search on available genome sequences identified ompA as the most highly scoring target. An antisense interaction between $4+12$ nucleotides (nt) in the $5^{\prime}$-region of MicA and the ShineDalgarno region in the 5 '-UTR of $0 \mathrm{mpA}$ mRNA was suggested, as exemplified in Figure 2B, and a complete data set is given in Supplementary Tables S1 and S3. Notably, MicA sequences differ substantially between bacteria. However, base changes are often located in singlestranded regions/loops, or occur as compensatory changes when in stem regions (Supplementary Table S1). Therefore, the secondary structure of MicA appears to be highly conserved, as is the putative region of interaction with ompA mRNA. All RNA/RNA hybrids suggested by this analysis conform to the same pattern of base pairs, including a bulged-out nucleotide (usually an A residue). In two bacterial species, Erwinia carotovora and Klebsiella pneumoniae, compensatory changes in both MicA and the $\operatorname{ompA}$ target maintain base-pairing (Supplementary Tables S1, S3). Taken together, the effect of MicA overexpression on OmpA protein levels (Fig. 2A) and the bioinformatics-aided target search (Fig. 2B; Supplementary Table S1) strongly suggest that MicA is an antisense regulator of $\operatorname{omp} A$.

\section{Deletion of micA results in loss of ompA mRNA regulation in stationary phase}

The ompA gene is down-regulated approximately fourfold upon entry into stationary phase; this effect has been postulated to be due to changes in ompA mRNA stability (Vytvytska et al. 1998, 2000). Based on the above findings, this could be explained by MicA acting as a negative regulator of $o m p A$ mRNA, since this sRNA is known to accumulate upon entry into stationary phase (Argaman et al. 2001). If so, ompA mRNA levels should fail to decrease in stationary phase when MicA is absent. Figure 3 shows a Northern blot analysis of ompA mRNA levels from cultures at different stages of growth. Probing for tmRNA was used as a loading control. As expected, the abundance of $\operatorname{omp} A$ mRNA signals decreased four- to fivefold when cells reached $\mathrm{OD}_{600}$ values of 1.52.0. In contrast, the isogenic $\Delta$ micA strain failed to exhibit a significant $\operatorname{omp} A$ down-regulation in stationary phase.

\section{MicA-mediated regulation of ompA requires $H f q$}

Growth-rate-dependent regulation of $\operatorname{omp} A$ mRNA stability has been the subject of several studies (Nilsson et al. 1984; Vytvytska et al. 1998, 2000). Destabilization of the message appears to be initiated by the endoribonuclease RNase E. Vytvytska et al. (2000) proposed that the Hfq protein is responsible for regulation of ompA mRNA decay during slow growth and in stationary phase. In their model, Hfq binding within the $5^{\prime}$-UTR interferes with ribosome binding, which, in turn, leads to deprotection of a nearby RNase E cleavage site. Consequently, decay is accelerated. In the light of our findings, the same data set might be open to a different interpretation, since many trans-encoded antisense RNAs require Hfq for activity. To define the principal regulator
A

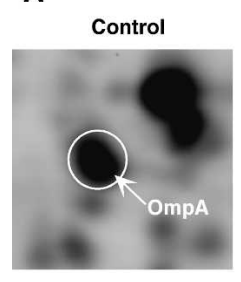

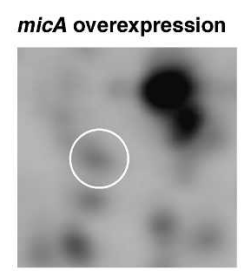

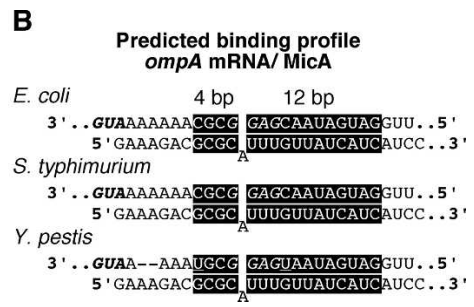

Figure 2. $о m p A$ is a likely target for MicA-mediated regulation. (A) MicA-dependent changes in the level of the OmpA protein. Relevant sections of two-dimensional-polyacrylamide gel-electrophoresed bulk protein from strain $\mathrm{MC}^{2} 100 \mathrm{relA}{ }^{+}$carrying either the pControl (left) or the pMicA plasmid (right) are shown. Protein samples from four replicates each were pooled, labeled with Cy3 (pControl) and Cy5 (pMicA), and electrophoresed as described in Materials and Methods. The images were obtained from scans at wavelengths of $580 \mathrm{~nm}(\mathrm{Cy} 3)$ and $670 \mathrm{~nm}$ (Cy 5). OmpA is encircled. (B) Bioinformatics indicates conservation of predicted antisense-sense RNA pairing. The predicted paired region ( $4+12$ motif) is indicated by nucleotides in black boxes. The upper strands are ompA mRNA leader sequences (right to left, $5^{\prime}$ to $\left.3^{\prime}\right)$, and the lower strands are MicA sequences (left to right, $5^{\prime}$ to $3^{\prime}$ ). The complete genomic sequences encoding these regions in E. coli, Salmonella typhi, and Yersinia pestis are given in Supplementary Tables S1 and S2. The 5'-GAGG Shine-Dalgarno sequences are indicated in italics, the AUG start codons are shown in bold/italics, nucleotide changes between species are underlined, and hyphens indicate a 2-nt deletion in Y. pestis. 


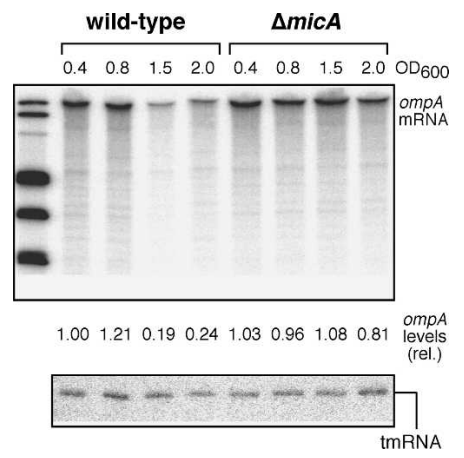

Figure 3. Loss of stationary phase regulation of ompA mRNA stability in a $\triangle m i c A$ background. The upper panel shows an autoradiogram of a Northern blot analysis, probed for ompA mRNA. The two isogenic wild-type and $\triangle$ micA bacterial cultures were grown to the $\mathrm{OD}_{600}$ values indicated. RNA extraction, Northern blotting, and quantitation of hybridization signals were done as described in Materials and Methods. Relative values of ompA mRNA signals, corrected for tmRNA signals, are indicated. The signal obtained in the wild-type strain at $\mathrm{OD}_{600}=0.4$ was set to unity. The marker on the left-hand side was radiolabeled pUC mix marker 8 DNA (Fermentas). The major bands from top to bottom in base pairs are $1116,883,501$, 404, and 331. (Lower panel) The same membrane probed for tmRNA as loading control.

of $o m p A$, we used a parallel analysis in isogenic $h f q$ proficient and $h f q$-deficient strains, analyzing simultaneously the levels of ompA mRNA, MicA, Anti-MicA, and tmRNA (as loading controls) on Northern blots (Fig. 4A), and membrane protein preparations on one-dimensional SDS-polyacrylamide gels (Fig. 4B). The two strains either lacked plasmids, or carried either the pMicA, pAnti-MicA, or the pControl plasmid. Cells were harvested in logarithmic phase $\left(\mathrm{OD}_{600}=0.2\right.$; a point in the growth phase at which ompA is not normally down-regulated) and processed for RNA or protein extraction.

Figure 4A shows subsequent probing of the same membrane for ompA mRNA, Anti-MicA, MicA, and tmRNA (loading control). High levels of MicA ( $>60$-fold higher than in the plasmid-free strain) were produced when cells contained pMicA, whereas MicA RNA was almost entirely absent when Anti-MicA was produced at high levels. Out-titration of MicA by its complement (Anti-MicA) is due to in vivo cleavage of the resulting RNA duplex by RNase III (data not shown). The Northern blots clearly indicate that, in the $h f q$-proficient strain, high MicA concentrations result in a strongly decreased ompA mRNA level. In contrast, significant down-regulation of ompA mRNA is not observed in the $\Delta h f q$ strain derivative even at high MicA concentrations (Fig. 4A, $\Delta h f q$, pMicA). For unknown reasons, ompA mRNA (Fig. 4A, wild type, pAnti-MicA) and OmpA protein levels were slightly decreased in some experiments when pAnti-MicA was present.

Figure $4 \mathrm{~B}$ shows the band pattern of the three major outer membrane proteins in all strains. Congruent with the results from the Northern blot, OmpA was almost entirely absent when MicA was overproduced and Hfq was present (Fig. 4B, wild type, pMicA). In the absence of Hfq, OmpA levels stayed high even at high concentrations of MicA (Fig. 4B, $\Delta h f q$, pMicA) suggesting that this protein is required for control. Thus, a comparison of the effects on ompA mRNA levels and OmpA protein accumulation in the different strain/plasmid combinations indicates that MicA is the principal regulator of $\operatorname{omp} A$, but that the Hfq protein is required for activity. An experiment conducted on stationary phase samples gave the same results (data not shown).

\section{Secondary structure analysis of MicA}

The above analyses suggested MicA to be an antisense RNA targeting the ompA mRNA. Since the predicted target site is overlapping the ompA TIR, this would suggest inhibition of translation as the primary effect to account for these results. To gain insight into MicA's mechanism of action, structural analyses were carried out. 5'-End-labeled MicA RNA was subjected to structural probing in solution, using RNase T1, RNase T2, and lead (II) acetate. The experimental data are shown in Supplementary Figure S1A, and a schematic summary of the secondary structure of MicA is shown in Figure 5. Chemical and enzymatic probing results were essentially consistent with the conformation predicted by MFold (Zuker 2003), and additional support was obtained from comparative analyses of the MicA-homolo-

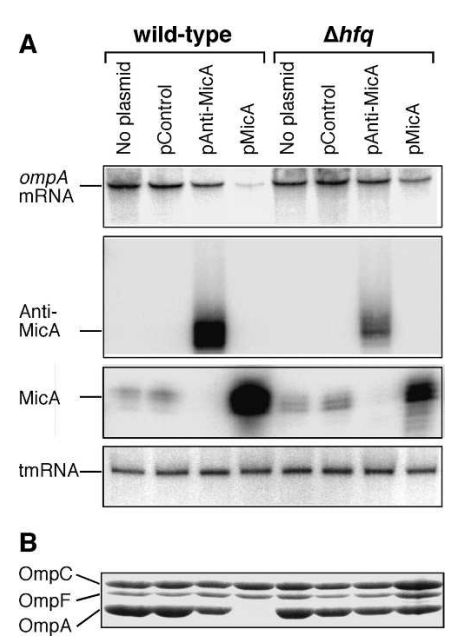

Figure 4. MicA- and Hfq-dependent down-regulation of ompA mRNA and OmpA protein. Cultures containing either a wildtype strain of $E$. coli, or its isogenic $\Delta h f q$ derivative, carrying plasmids as indicated above the figure, were grown to an $\mathrm{OD}_{600}$ value of 0.2 and harvested. Extractions were conducted in parallel, giving total RNA used for the Northern blots in $A$, and membrane protein preparations $(B)$. $(A)$ The same membrane was probed successively for ompA mRNA, Anti-MicA, MicA, and tmRNA (loading control). The radioactive probes used are described in Materials and Methods, and Supplementary Table S4. (B) Section of a one-dimensional PAGE gel (Materials and Methods) stained with Coomassie Brilliant Blue. The positions of the OmpC, OmpF, and OmpA bands are indicated. 


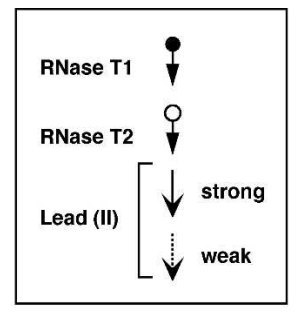

5 5'

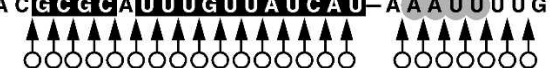

Figure 5. Secondary structure of MicA. The secondary structure of MicA shown here is based on mapping data in Supplementary Figure S1. RNase T1, T2, and lead(II) cleavages are shown. Nucleotides encircled in gray vary in MicA RNAs from different bacterial species (Supplementary Table S1). Nucleotides in black boxes are complementary to the ompA RNA leader.

gous sequences in Klebsiella, Shigella, Salmonella, Yersinia, Enterobacter, and Serratia species (Supplementary Table S1). Phylogenetic conservation suggests the determined secondary structure motifs of MicA with two stable stem-loops preceded by an $\approx 23$-nt-long unstructured 5 '-tail. Sequence variation occurs mostly in regions predicted to be single-stranded (i.e., loops I and II, and the linker region between hairpins I and II) (grayfilled circles in Fig. 5).

MicA binds to and base-pairs with the ompA translational initiation region

Given that MicA exhibits significant sequence complementarity to the ompA TIR (Fig. 2B), and that this putative binding motif lies in an accessible, unstructured $5^{\prime}$ tail (Fig. 5), binding of in vitro transcribed MicA and ompA mRNA leader can be expected. Figure 6A shows autoradiograms of gel shift experiments, using either $5^{\prime}$ end- $\left[{ }^{32} \mathrm{P}\right]$-labeled MicA and increasing concentrations of unlabeled ompA RNA, or the same combinations in reverse $\left(5^{\prime}\right.$-labeled ompA RNA, increasing concentrations of MicA). Binding assays were carried out at $37^{\circ} \mathrm{C}$, and complex formation was monitored as slower migration on native gels. With both experimental protocols, a retarded MicA-ompA RNA complex was obtained. Figure $6 \mathrm{~B}$ shows time courses of MicA binding at two different concentrations of the unlabeled target RNA / 10 and 100 $\mathrm{nM}$ ). From this experiment, we calculated the secondorder binding rate constant, $k_{\text {app }}$ (see Persson et al. 1988) to be $\approx 6 \times 10^{4} \mathrm{M}^{-1} \mathrm{sec}^{-1}$. This value is $\sim 10$-fold lower than those characteristic of many known antisense-target RNA pairs (Wagner et al. 2002).

To map the region of interaction, structural probing was used. $5^{\prime}$-End- $\left[{ }^{32} \mathrm{P}\right]-$ labeled $o m p A$ RNA was incubated in the presence or absence of unlabeled MicA, and the incubations were treated with lead(II) acetate, RNase $\mathrm{T} 1$, or RNase T2 (data not shown for T2). A comparison of the cleavage patterns showed that MicA addition resulted in a "footprint." T1 as well as lead(II) cleavages were strongly decreased in the region of ompA mRNA predicted to be base-paired to the sRNA (region O/M indicated in brackets in Fig. 7A). A schematic drawing of the resulting complex, based on the structure mapping experiments, is shown in Figure 7B. The reverse experiment (structure mapping of labeled MicA in the presence and absence of ompA mRNA) is shown in Supplementary Figure S1B and corroborates that the $5^{\prime}$-most stemloop of MicA refolds upon ompA RNA binding as shown (Fig. 7B). All results support the phylogenetically suggested base-pairing scheme (Fig. 2B).

\section{Mutational analysis supports antisense-target pairing in vivo}

To assess MicA-ompA base-pairing in the cell, we resorted to reporter gene fusion experiments. Plasmid pOmpLac (Table 1) is a p15A-based replicon that carries an ompA-lacZ translational fusion and therefore serves as a readout for OmpA synthesis. Six base changes were introduced into the MicA target region to give pOmpLacM6. MicA was provided from pMicA (compatible with pOmpLac) or the correspondently mutated pMicA-M6. Putative mutant-wild-type RNA interactions have six mismatches compared to the matched RNA combinations (Supplementary Fig. S3). $\beta$-Galactosidase measurements were carried out on extracts from exponentially growing cultures carrying either of pOmpLac or pOmpLac-M6, together with pControl, pMicA, or pMicA-M6. Table 2 summarizes these results. When wild-type MicA

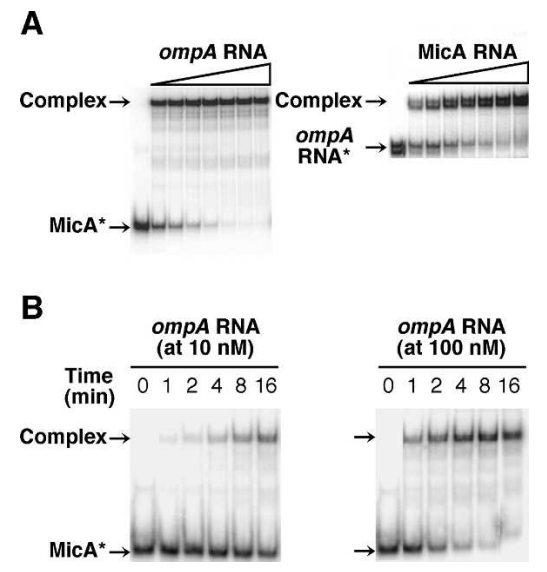

Figure 6. MicA-ompA RNA gel shift assays. (A, left) Labeled MicA was incubated for $30 \mathrm{~min}$ at $37^{\circ} \mathrm{C}$ with increasing concentrations of unlabeled ompA RNA, followed by electrophoresis on native gels. (Right) The reverse experiment. The concentration range of the unlabeled RNA in both cases was $0,5,10$, $20,40,80,160$, and $320 \mathrm{nM}$. The panels show autoradiograms of such experiments. (B) Time-course experiments in which unlabeled ompA RNA was present at 10 or $100 \mathrm{nM}$, and labeled MicA at $<0.5 \mathrm{nM}$, to ensure pseudo-first-order kinetics. Analyses and calculations were performed as described in Materials and Methods. 


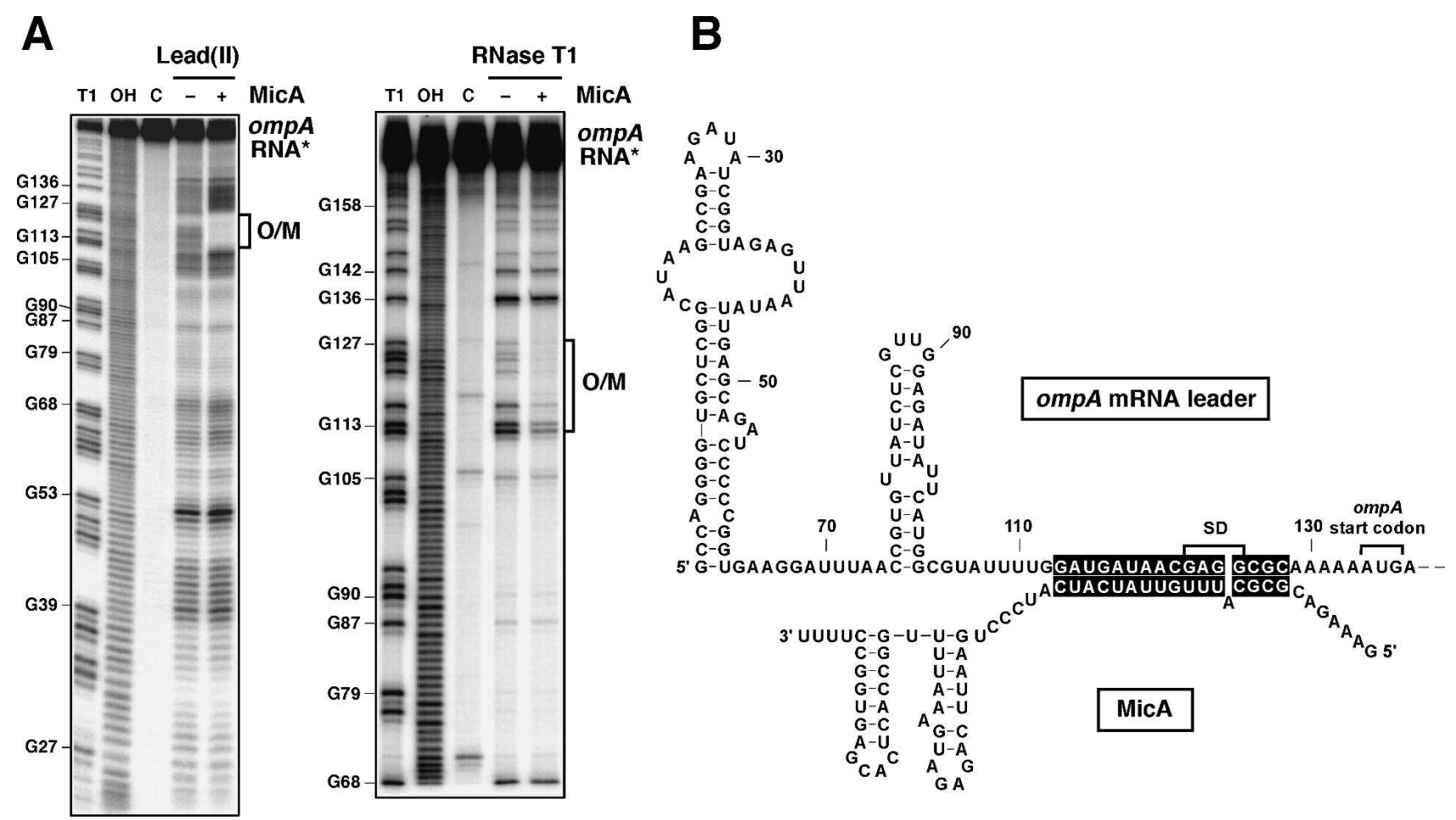

Figure 7. Structure mapping of the MicA-ompA RNA complex. (A) The two autoradiograms show structure probing with lead(II) and RNase T1, conducted on 5'-end-labeled ompA mRNA leader. (+ and -) Indicate the presence or absence, respectively, of unlabeled MicA RNA in the incubation prior to treatment. (T1) RNase T1 cleavage under denaturing conditions; $(\mathrm{OH})$ an alikaline ladder; (C) mock-treated control RNA. Some nucleotide positions are given for orientation. (O/M) The ompA mRNA region protected by bound MicA. (B) Secondary structure model based on $A$ and additional experiments. The model is consistent with Chen et al. (1991). The interaction site is highlighted by black boxes. The ompA Shine-Dalgarno sequence and the AUG start codon are indicated. The downstream region is omitted. The single G residues added at the 5'-ends of MicA and ompA RNA (see Materials and Methods) are not shown.

was present (pMicA), OmpA-LacZ synthesis from pOmpLac was repressed fivefold, whereas mutant MicA (pMicA-M6) barely affected the wild-type target. Similarly, repression of target mutant OmpA-LacZ activity (pOmpLac-M6) by wild-type MicA was inefficient, but repression was restored by the presence of pMicA-M6. Thus, the effect of the compensatory mutations corroborates the antisense-target interaction proposed based on the in vitro results.

\section{MicA blocks ribosome binding to the ompA translation initiation region}

MicA binding to the TIR, overlapping the ompA ShineDalgarno sequence, is expected to interfere with initiation of translation. As a test for MicA-dependent inhibition, we used a toeprinting assay (Hartz et al. 1988). Figure 8 shows that in the presence of initiator tRNA ${ }^{\text {fMet }}$, 30 S ribosomal subunits bound to the ompA TIR and blocked reverse transcription of a labeled primer, annealed downstream, at the characteristic position +16 (start codon $\mathrm{A}$ is +1 ). This signal provides a measure for the formation of the ternary complex, since it is dependent on both 30S subunits and initiator tRNA. Addition of MicA prior to the addition of $30 \mathrm{~S}$ subunits and

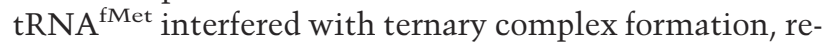

sulting in a weaker toeprint signal (Fig. 8). Addition of a noncognate sRNA, SraI/RyhB (Argaman et al. 2001; Wassarman et al. 2001), failed to decrease the toeprint signal, indicating that MicA-dependent inhibition of ribosome binding was specific. Incidentally, the lanes containing MicA show a second "toeprint" that delineates the leading edge of the MicA/ompA base-paired region. Thus, this assay indicates that the base-pairing of MicA to its target sequence within the $o m p A$ leader RNA directly interferes with the formation of translational initiation complexes.

\section{Discussion}

In this paper, we revisited the regulation of the ompA gene, encoding one of the three major outer membrane proteins in E. coli. Two porins, $\mathrm{OmpF}$ and $\mathrm{OmpC}$, had previously been shown to be oppositely regulated during various stress responses (Delihas and Forst 2001; Chen et al. 2004). Both of their genes are under transcriptional control, but are additionally regulated at the post-transcriptional level by two antisense RNAs, MicF and $\mathrm{MicC}$, respectively. In contrast, in addition to transcriptional regulation by cAMP-CRP (Gibert and Barbe 1990), $o m p A$ is growth-rate-regulated. This effect appears to be exerted, primarily or exclusively, by control of the deg- 
Table 1. Strains and plasmids

\begin{tabular}{|c|c|c|c|}
\hline Strain name & Bacteria & Genotype/phenotype & Source or reference \\
\hline MC4100 & E. coli & 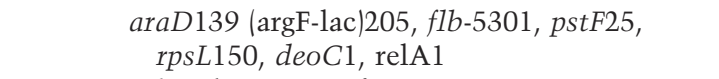 & T. Nyström \\
\hline MC4100relA $^{+}$ & E. coli & relA $A^{+}$derivative of $\mathrm{MC} 4100$ & T. Nyström \\
\hline MC4100hfq & E. coli & $\Delta h f q\left(\mathrm{Cm}^{\mathrm{R}}\right)$ derivative of $\mathrm{MC} 4100$ & This study \\
\hline G897 & E. coli & MC4100 relA ${ }^{+} \Delta \operatorname{mic} A\left(\mathrm{Cm}^{\mathrm{R}}\right)$ & This study \\
\hline G960 & E. coli & MC4100 relA ${ }^{+} \Delta h f q\left(\mathrm{Cm}^{\mathrm{R}}\right)$ & This study \\
\hline LT2 & Salmonella typhimurium & & Laboratory stock \\
\hline CCUG 38136 & Enterobacter cloacae & Clinical isolate & Laboratory stock \\
\hline V311-1051 & Serratia marcescens & Clinical isolate & Laboratory stock \\
\hline CCUG 43275 & Yersinia enterocolitica & Clinical isolate & Laboratory stock \\
\hline Plasmid trivial name & Plasmid name & Properties & Source/reference \\
\hline pMicA & pJV150IG-34 & $\begin{array}{l}\text { pZE12-luc derivative }\left(\mathrm{ColE} 1, \mathrm{Amp}^{\mathrm{R}}\right) \\
P_{\text {Llaco }} \text { promoter, } m i c A \text { insert }\end{array}$ & This study \\
\hline pAnti-MicA & pJV721-2 & $\begin{array}{l}\text { As above but reverse micA insert followed } \\
\text { by } r r n B \text { terminator }\end{array}$ & This study \\
\hline pControl & pJV968-1 & As above but lacking promoter, carries lacZ fragment & Vogel et al. 2004 \\
\hline pMicA-M6 & & Carries M6 mutation in antisense sequence in pMicA & This study \\
\hline pOmpLac & & Translational ompA-lacZ fusion (in pMC874, $\mathrm{Km}^{\mathrm{R}}$ ) & This study \\
\hline pOmpLac-M6 & & $\begin{array}{l}\text { Translational ompA-lac } Z \text { fusion pOmpLac with } \\
\text { target mutation M6 }\end{array}$ & This study \\
\hline
\end{tabular}

radation rate of ompA mRNA (Nilsson et al. 1984). Specifically, the rate-limiting step in decay of this message was assigned to the endoribonuclease RNase E (Melefors and von Gabain 1988). The Bläsi lab conducted in vitro experiments to further elucidate the mechanism by which mRNA degradation could be differentially affected (Vytvytska et al. 2000). They found that, in vitro, Hfq prevented ribosome binding to the ompA TIR. This, in turn, was supposed to promote the rapid decay at low growth rates observed in vivo.

The findings reported here offer an alternative explanation and resolve problems with the earlier model. We found that one of the recently discovered sRNAs, MicA (previously SraD) (Argaman et al. 2001), is an antisense inhibitor of ompA expression. This conclusion is based on in vivo and in vitro experiments, and gains additional support from bioinformatics. Firstly, overexpression of MicA down-regulates synthesis of the OmpA protein by $\approx 10$-fold (Fig. 2A). Additionally, the level of the signal peptide of OmpA (which accumulates as a separate spot on $2 \mathrm{D}$ gels) was decreased by $>80$-fold (data not shown). MicA overexpression also drastically decreases the abundance of the ompA mRNA, and the OmpA protein, in an Hfq-dependent fashion (Fig. 4). Upon deletion of the micA gene, down-regulation in stationary phase is lost (Fig. 3), which cannot easily be reconciled with a direct effect of Hfq according to Vytvytska et al. (2000). Secondly, in vitro studies show that MicA binds specifically to the ompA mRNA leader (Fig. 6) and that the complex formed comprises precisely the antisense and target RNA nucleotides predicted from a phylogenetic analysis (Figs. 2B, 7). When this antisense/target RNA complex is formed, ribosomes are unable to bind to the ompA TIR in vitro (Fig. 8). The proposed antisense-target RNA interaction is further supported by compensatory mutations in vivo (Table 2). Thus, we propose that MicA is the principal post-transcriptional regulator of the ompA gene, and that the Hfq protein is required as an important coregulator (see Fig. 4).

The model of the Bläsi group (Vytvytska et al. 2000) is based primarily on four experimentally observed effects of purified Hfq: (1) Ribosomes can protect ompA mRNA from RNase E cleavage; (2) Hfq binds to the ompA leader; (3) this binding inhibits an ompA toeprint; and (4) Hfq inhibits OmpA translation in a bacterial extract. To account for the in vivo regulation, the authors postulate that Hfq concentration increases toward entry into stationary phase and at low growth rates. Thus, Hfq binding would progressively inhibit ompA translation, and hence the absence of ribosomes would de-protect an RNase E cleavage site, thus facilitating the onset of decay. This

Table 2. MicA-dependent regulation of ompA-lacZ expression in vivo

\begin{tabular}{lllc}
\hline $\begin{array}{l}\text { ompA-lacZ } \\
\text { fusion } \\
\text { plasmid }\end{array}$ & $\begin{array}{c}\text { MicA donor } \\
\text { plasmid }\end{array}$ & $\begin{array}{l}\text { Combinations } \\
\text { (ompA/MicA) }\end{array}$ & $\begin{array}{c}\text { Relative } \\
\beta \text {-galactosidase } \\
\text { activity }\end{array}$ \\
\hline pOmpLac & pControl & $\mathrm{wt} /-$ & $1.00^{\mathrm{a}}$ \\
pOmpLac & pMicA & $\mathrm{wt} / \mathrm{wt}$ & 0.20 \\
pOmpLac & pMicA-M6 & $\mathrm{wt} / \mathrm{M} 6 \mathrm{mut}$ & 0.85 \\
pOmpLac-M6 & pControl & M6 mut/- & $1.00^{\mathrm{a}}$ \\
pOmpLac-M6 & pMicA & M6 mut/wt & 0.81 \\
pOmpLac-M6 & pMicA-M6 & M6 mut/M6 mut & 0.22
\end{tabular}

(wt) Wild type; (mut) mutant.

${ }^{a}$ The specific activity obtained with these strain/plasmid combinations was set to unity. The ratio of activities of pOmpLac$\mathrm{M} 6 / \mathrm{pControl} \mathrm{over} \mathrm{pOmpLac/pControl} \mathrm{was} \mathrm{0.95.} \mathrm{Values} \mathrm{are} \mathrm{av-}$ erages from three independent experiments (deviations ranged from $5 \%$ to $20 \%$ ). 
Udekwu et al.

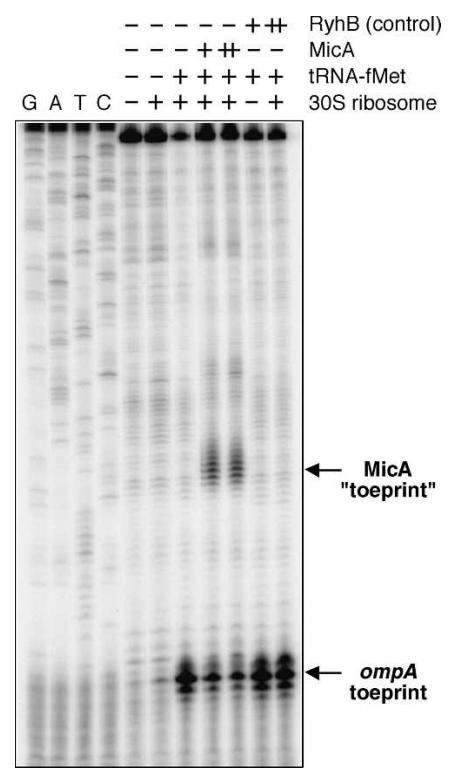

Figure 8. MicA blocks ribosome binding to the ompA TIR. An autoradiogram of a toeprint analysis is shown (for details, see Materials and Methods, and Results). Addition of $30 \mathrm{~S}$ ribosomal subunits, initiator tRNA, MicA, or RyhB (as control RNA) is indicated by + . Increased concentrations (for MicA/RyhB) are indicated by ++. GATC lanes are sequencing ladders obtained using the same radiolabeled primer as in the toeprint analysis.

interpretation is in conflict with two other reports that report on two- to fourfold decreased Hfq concentrations in stationary phase (Kajitani et al. 1994; Ali Azam et al. 1999|-if so, the opposite effect would be expected. Since growth rate regulation of $\mathrm{omp} A$ is lost in a $\triangle m i c A$ strain although the $h f q$ gene is wild type (Fig. 3), Hfq cannot be the sole regulator. In contrast, MicA RNA has the appropriate properties to account for regulation: Its abundance increases upon entry into stationary phase (Argaman et al. 2001), and this correlates with a corresponding decrease of ompA mRNA observed here and by others (Nilsson et al. 1984). Thus, the model proposed here interprets $о m p A$ regulation as a competition between MicA and initiating ribosomes (Fig. 9). Upon entry into stationary phase, MicA RNA accumulates, and bindspossibly aided in this step by $\mathrm{Hfq}$ - to its target site within the ompA mRNA leader. Binding blocks translation initiation. This by itself would entail a decrease in OmpA synthesis, but in addition, the absence of ribosome binding is expected to be responsible for the RNase E-dependent accelerated decay observed in many studies. In logarithmic phase, when MicA is at low concentration, ribosomes compete successfully for the ompA TIR, resulting in translation and, simultaneously, protection from RNase E (Vytvytska et al. 2000).

The precise role of Hfq in MicA-mediated regulation remains to be resolved-a problem that this system shares with several other sRNA-regulated systems in which $h f q$-dependence was observed (Gottesman 2004; Valentin-Hansen et al. 2004). Hfq binds to many sRNAs, and often also to their target RNAs. It is known to dras- tically affect the stabilities of several sRNAs (in some cases by competing for RNase E cleavage sites), which might be sufficient to explain the observed impact on regulation (Wagner and Vogel 2003). However, some sRNAs are not stabilized, yet the presence of an intact $h f q$ gene is required for regulation. This may be related to chaperone-like effects, such as unfolding of RNA elements critical for interaction (Moll et al. 2003b; Geissmann and Touati 2004), or molecular crowding effects that rely on protein-mediated association prior to basepairing. Alternatively, RNA-RNA complexes could be stabilized (lower dissociation rates) or formed more rapidly (higher association rates). Enhancement of Spot 42/ galK mRNA and OxyS/fhlA mRNA binding has been demonstrated in vitro (Møller et al. 2002; Zhang et al. 2002), whereas a quantitative binding kinetics analysis of DsrA/rpoS mRNA gave only a twofold effect (Lease and Woodson 2004). In vitro binding of MicA to ompA RNA occurs in the absence of, and is not significantly affected by, purified Hfq, although this protein binds both RNAs with high affinity (Fig. 6; data not shown). The binding rate constant obtained (Fig. 6B) indicates moderate efficiency of the regulator, which is in line with a mere fourfold regulation at the maximum MicA levels in stationary phase (Fig. 3; Nilsson et al. 1984; Vytvytska et al. 1998, 2000); a similar binding rate constant was recently reported for DsrA/rpoS mRNA (Lease and Woodson 2004). Overproduced MicA RNA (and

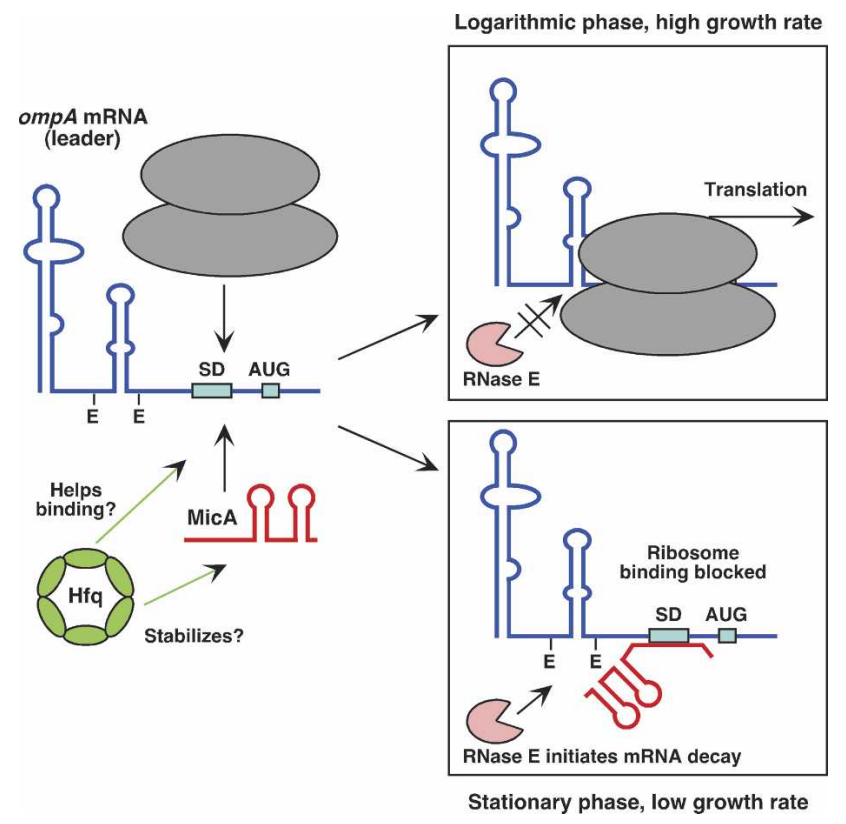

Figure 9. Model for MicA-dependent regulation of ompA. A model for post-transcriptional regulation of $o m p A$ by MicA is shown. The left-hand side indicates that MicA competes with ribosomes for access to the ompA TIR. The involvement of Hfq is indicated (for details, see Discussion). The two alternative scenarios, representing logarithmic growth or stationary phase, are indicated in the two boxes. Two RNase E cleavage sites previously identified (e.g., Moll et al. 2003a) are labeled E. The model is described in full in the text. 
Anti-MicA) shows an approximately threefold stabilization when $h f q$-proficient and $h f q$-deficient strains are compared (Fig. 4), although the basal levels of MicA are only insignificantly affected. We also noted that MicA is slightly more heterogeneous in size in the $\Delta h f q$ compared with the wild-type strain, although the significance of this observation is not clear. Work is in progress to address the molecular mechanism by which Hfq aids MicA-dependent function.

This study addressed the regulatory role and mechanism of MicA in E. coli. Sequence comparisons to other enterobacteria predict micA and ompA genes (with characteristic leader regions) to be present (Supplementary Tables S1, S3). It is striking that significant sequence changes are tolerated, but that the experimentally determined site of interaction (Fig. 7) maintains putative basepairing capacity, following the $12+4$ base-pair motif overlapping the Shine/Dalgarno sequence. Thus, we suggest that MicA RNAs are present in many bacteria, and that they act on ompA mRNAs. As a pilot experiment, we used available laboratory strains and probed for MicA at lowered stringency. All bacteria tested (Supplementary Fig. S2) gave hybridization signals in the predicted size range, and all but Serratia marcescens showed MicA induction in stationary phase. The general biological significance of a conserved regulatory pathway involving MicA and ompA is still unclear. The synthesis of the two classical trimeric porins, $\mathrm{OmpF}$ and $\mathrm{OmpC}$, is regulated in response to various stresses, and certainly adaptive changes in membrane properties make sense in such a scenario. Slow growth and entry into stationary phase also represents a stress situation that might call for corresponding changes. OmpA appears to be "porin-like," forming monomeric diffusion channels (Sugawara and Nikaido 1992), and serves as a phage receptor (Riede et al. 1985). Deficiency in OmpA sometimes affects virulence traits (Wang and Kim 2002) and the tolerance levels toward certain antibiotics.

In summary, we have identified a target of yet another sRNA in E. coli. Together with the recent discovery of $\mathrm{MicC}$ as a regulator of $\operatorname{omp} C$, three of the major outer membrane protein genes are now known to be regulated by antisense RNAs. All of these are induced/accumulate in particular stress conditions, and all target functionally equivalent regions in their respective target RNAs. Since several additional outer membrane protein mRNAs are predicted to carry structurally similar leader extensions, we speculate that several additional sRNAs may be involved in their regulation.

\section{Materials and methods}

\section{Chemicals, reagents, and oligodeoxyribonucleotides}

All chemicals and reagents were purchased from Sigma-Aldrich or GE-Healthcare unless otherwise specified. Oligodeoxyribonucleotides were purchased from Sigma-Genosys.

\section{Bacterial strains and plasmids}

The bacterial strains and plasmids used in this study are listed in Table 1. The E. coli strain MC4100relA ${ }^{+}$was used as wild type unless otherwise stated. E. coli MC4100 hfq::cat and K12 micA::cat (kindly provided by S. Altuvia, Hebrew University, Jerusalem, Israel) were used to move alleles into MC4100 relA ${ }^{+}$ by $\mathrm{P} 1$-mediated transduction. Plasmids used for overexpression of MicA (pMicA), its complement Anti-MicA (pAnti-MicA), and the control plasmid pControl carrying a promoterless lac $Z$ fragment were constructed as described previously (Vogel et al. 2004). For plasmid pMicA, primers JB-150-I and JB-150-G were used to amplify the micA gene. The resultant PCR fragment carried a $5^{\prime}$-phosphate at one end for blunt-end ligation to the plasmid vector, and a KpnI overhang was generated by cleavage near the other end. The insert was ligated into the pZE12-luc plasmid vector as described (blunt/KpnI site) (Lutz and Bujard 1997). Plasmid pAnti-MicA was constructed in the same way using primers JB-150-N and JB-150-O. In these plasmids, the initiation site of the encoded RNA lies at position +1 of the constitutive PLlacO promoter of pZE12-luc. The pControl plasmid lacks the PLlacO promoter. Regions inserted into the overexpression plasmids are shown schematically in Figure 1A. In pMicA, termination of MicA occurs at its own Rho-independent terminator. In pAnti-MicA, the insert is followed by a strong ribosomal $(r r n B)$ terminator. Inserts were verified by dideoxy sequencing. The translational ompA-lac $Z$ fusion plasmid pOmpLac was constructed as follows. A 274-bp fragment containing the promoter and ompA leader region to the 12th ompA codon was generated by PCR with primers ompAfwd and ompArev (Supplementary Table S4), cleaved with BamHI, and inserted into the unique BamHI site of vector pMC874 (Casadaban et al. 1980). Insertion is in-frame with the 8th codon of lacZ. Plasmid pOmpLac-M6, containing six base substitutions in the MicA target sequence, was constructed by site-specific mutagenesis (QuikChange XL kit; Stratagene) using oligodeoxyribonucleotide OmpA-M6[+] and OmpA-M6[-]. The complementary changes were introduced into pMicA (with MicA-M6[+] and MicA-M6[-]) to generate pMicA-M6.

\section{Media and growth conditions}

Unless otherwise specified, cells were grown aerobically at $37^{\circ} \mathrm{C}$ in either L broth or M9 medium supplemented with $0.2 \%$ glucose, $0.2 \%$ casamino acids, $1 \mathrm{mM} \mathrm{MgSO}_{4}, 0.1 \mathrm{mM} \mathrm{CaCl}_{2}$, and $1 \mu \mathrm{g} / \mathrm{mL}$ thiamine. Bacterial growth was monitored by measuring optical density at $\mathrm{OD}_{600}$. When required, antibiotics were added at $50 \mu \mathrm{g} / \mathrm{mL}$ (ampicillin), $30 \mu \mathrm{g} / \mathrm{mL}$ (chlorampheni$\mathrm{col})$, and $12.5 \mu \mathrm{g} / \mathrm{mL}$ (tetracycline), respectively.

\section{ß-Galactosidase assay}

Plasmid-containing cells were grown exponentially in L Broth and harvested at $\mathrm{OD}_{600}=0.3$. OmpA-LacZ translational fusion activity was assayed as described (Berzal-Herranz et al. 1991).

\section{One-dimensional SDS-PAGE of E. coli membrane proteins}

Overnight cultures of wild-type or $\Delta h f q$ strains, either plasmidfree or transformed with plasmids pMicA, pAnti-MicA, and pControl, respectively, were diluted 200-fold in L Broth. Growth was continued until $\mathrm{OD}_{600}$ reached either 0.2 or 1.5. Cells were chilled rapidly on ice and pelleted for $15 \mathrm{~min}$ at $5000 \mathrm{~g}\left(4^{\circ} \mathrm{C}\right)$. The total membrane protein fraction was extracted essentially as described (Matsuyama et al. 1984). Protein concentration was determined using the Bradford method. Equal amounts of protein were run on $10 \%$ SDS-polyacrylamide gels containing $4 \%$ Urea at $100 \mathrm{~V}$. The gel was then stained overnight (staining solution $0.06 \%$ [w/v] Coomassie Brilliant Blue $\mathrm{R}-250,35 \%[\mathrm{v} / \mathrm{v}]$ 2-propanol, 15\% [v/v] acetic acid) and 
destained (12\% 2-propanol, 5\% acetic acid). The protocol for 2D-PAGE analysis of total protein (as in Fig. 2) is detailed in Supplemental Material.

\section{Northern blot analyses}

Growing cells were stopped in 0.2 volumes of RNA stop solution (5\% phenol, 95\% ethanol) at the desired $\mathrm{OD}_{600}$, pelleted, and frozen in liquid nitrogen. Total RNA was extracted using the hot acid-phenol method essentially as described (Blomberg et al. 1990). The total RNA was treated with RQ1 DNase (Promega), extracted with phenol, then chloroform, and finally precipitated in ethanol overnight at $-20^{\circ} \mathrm{C}$. The RNA was pelleted at $4^{\circ} \mathrm{C}$, washed with $75 \%$ ethanol, dried at room temperature, and resuspended in sterile RNase-free water. RNA loading buffer $(95 \%$ [v/v] formamide, $0.025 \%$ [w/v] bromophenol blue, $0.025 \%[\mathrm{w} / \mathrm{v}$ ] xylene cyanol, $5 \mathrm{mM}$ EDTA at $\mathrm{pH} 8.0,0.025 \%$ $[\mathrm{w} / \mathrm{v}] \mathrm{SDS}$ ) was added at a 1:1 ratio to each sample. Samples were electrophoresed under denaturing conditions on $5 \%-6 \%$ polyacrylamide gels containing $7 \mathrm{M}$ urea. Gels were electroblotted (Bio-Rad Trans-Blot cell) onto Nylon $\mathrm{N}+$ membranes (GE Healthcare), and probed in modified Church and Gilbert hybridization buffer (Church and Gilbert 1984). Probing with DNA oligodeoxyribonucleotides was carried out at $42^{\circ} \mathrm{C}$ or with riboprobes at $65^{\circ} \mathrm{C}$ (at reduced stringency for the blot in Supplementary Fig. S2). Hybridized probes were visualized with a PhosphorImager, model 400S (Molecular Dynamics), and band intensities quantitated using the ImageQuant software, version 4.2a (Molecular Dynamics).

\section{Riboprobe generation}

The primers used to generate riboprobe transcription templates for Northern blot hybridizations are listed in Supplementary Table S4 [for ompA riboprobe: T7ompA-RP and ompA(+9)-RP; for MicA riboprobe: JB-150-N-T7 and JB-150-G; for Anti-MicA riboprobe: T7-MicA and MicA3']. Standard polymerase chain reactions were carried out on genomic DNA. Primers were designed to bracket desired sequences of ompA or micA (reverse orientation for anti-micA transcription). Forward primers contained additionally the phage T7 RNA polymerase promoter sequence. In vitro transcription was carried out on purified PCR products with a molar excess of $\alpha-{ }_{-}^{32}$ P-UTP over nonradioactive UTP. Reactions were performed with the T7-Maxiscript kit (Invitrogen). Riboprobes were purified on $12 \%$ PA-gels, eluted in RNA elution buffer $(0.1 \mathrm{M}$ sodium acetate at $\mathrm{pH} 5.7,10 \mathrm{mM}$ EDTA, $0.5 \%[\mathrm{w} / \mathrm{v}]$ SDS), phenol-extracted, precipitated in ethanol, and resuspended in RNase-free sterile water.

\section{Synthesis, purification, and labeling of RNA for in vitro structure mapping}

DNA templates carrying a T7 promoter sequence were generated by PCR using genomic DNA and primers as listed in Supplementary Table S4. For MicA, primers T7-MicA and MicA3' were used, and for ompA mRNA, primers KU21 and T7KU20ompA. For transcription templates generating RyhB RNA, we used primers T7RyhB and 3'RyhB. Note that for both MicA and ompA leader transcripts an additional $G$ residue is present; this G was included in the template for enhanced transcription efficiency. The ompA leader RNA transcript has a length of $172 \mathrm{nt}$. Large-scale in vitro synthesis of RNA was carried out as in Hjalt and Wagner (1995). Transcripts were dephosphorylated and 5 '-end-labeled with $\gamma{ }^{-32} \mathrm{P}$-ATP according to the manufacturer's protocol (GE Healthcare).

\section{Gel mobility shift assay}

Binding assays were performed in $1 \times$ TMN buffer $(20 \mathrm{mM}$ Trisacetate at $\mathrm{pH} 7.6,100 \mathrm{mM}$ sodium acetate, $5 \mathrm{mM}$ magnesium acetate) as follows: 5'-end-labeled RNA (0.05 pmol of MicA RNA or ompA leader mRNA) and $1 \mu \mathrm{g}$ of carrier yeast tRNA (Ambion) were incubated with increasing concentrations of unlabeled RNA (MicA or ompA leader) in $10 \mu \mathrm{L}$ at $37^{\circ} \mathrm{C}$ for $30 \mathrm{~min}$ (experiment in Fig. 6A). The binding reactions were mixed with $2 \mu \mathrm{L}$ of loading dye ( $48 \%$ glycerol, $0.01 \%$ bromophenol blue) and electrophoresed on native $5 \%$ polyacrylamide gels in $0.5 \times \mathrm{TBE}$ buffer at $200 \mathrm{~V}$ in a cold room for $3 \mathrm{~h}$. Gels were dried and analyzed using a PhosphorImager and the Image-quant software package (Molecular Dynamics). For determination of the second-order binding rate constant, $k_{\text {app }}$, time course experiments were conducted, using end-labeled MicA and unlabeled $о m p A$ leader RNA at either 10 or $100 \mathrm{nM}$ (in Fig. 6B). Aliquots were withdrawn at different time points and run as above. Calculations were made according to Persson et al. (1988).

Enzymatic and chemical probing of MicA and ompA mRNA leader

In total, $0.1 \mathrm{pmol}$ of $5^{\prime}$-end-labeled ompA mRNA leader, or MicA RNA, was incubated with $1 \mu \mathrm{g}$ of yeast RNA (Ambion) in $10 \mu \mathrm{L}$ of $\mathrm{TMN}$ buffer at $37^{\circ} \mathrm{C}$ for $15 \mathrm{~min}$. Subsequently, $2 \mu \mathrm{L}$ of a fresh solution of lead(II) acetate ( $25 \mathrm{mM}$; Sigma-Aldrich), $1 \mu \mathrm{L}$ of RNase T1 (0.01 U; Ambion), or RNase T2 (0.02 U; Invitrogen) were added, and incubations continued for 1, 2, or $5 \mathrm{~min}$. Reactions were stopped by adding $5 \mu \mathrm{L}$ of $0.1 \mathrm{M}$ EDTA. The RNAs were precipitated, dissolved in gel-loading buffer, and electrophoresed on $8 \%$ polyacrylamide/7 $\mathrm{M}$ urea sequencing gels run in $1 \times$ TBE. The same experimental method was used to analyze the complex between MicA and ompA RNA, except that the unlabeled RNA was present in $>20$-fold molar excess. G-specific cleavages used as markers were obtained under denaturing conditions, and alkaline hydrolysis ladders were obtained according to the manufacturer's protocol (Ambion).

\section{Toeprinting analysis}

Toeprinting assays were carried out as described (Hartz et al. 1988 ) with some modifications. Annealing mixtures in standard buffer (10 mM Tris-acetate at $\mathrm{pH} 7.6,0.1 \mathrm{M}$ potassium acetate, $1 \mathrm{mM}$ DTT) contained 2 pmol of unlabeled ompA mRNA leader and $0.5 \mathrm{pmol}$ of the $5^{\prime}$-end-labeled oligodeoxyribonucleotide KU21, which is complementary to the $3^{\prime}$ portion of the ompA RNA used. The annealing mixtures were heated for $1 \mathrm{~min}$ at $95^{\circ} \mathrm{C}$ and then chilled on ice for $5 \mathrm{~min}$, before addition of magnesium acetate (final concentration $10 \mathrm{mM})$ and dNTPs $(1 \mathrm{mM}$ each). After $5 \mathrm{~min}$ at $37^{\circ} \mathrm{C}, 2 \mathrm{pmol}$ of $30 \mathrm{~S}$ ribosomal subunits (kindly provided by Ayman Antoun) were added to the reaction mixture and incubated for $5 \mathrm{~min}$ at $37^{\circ} \mathrm{C}$. Uncharged fMettRNA (10 pmol) was added, and incubations continued for 25 min. Primer extension was conducted with Superscript II reverse transcriptase (200 units, Invitrogen) for $20 \mathrm{~min}$. Reactions were stopped, phenol-chloroform extracted, and cDNA precipitated in ethanol. The cDNA products were resuspended in $5 \mu \mathrm{L}$ of loading buffer II (Ambion), and run on $8 \%$ polyacrylamide/7 $\mathrm{M}$ urea gels. Toeprint signals were identified by comparison to sequence ladders generated from PCR-generated DNA templates, using the same $5^{\prime}$-end-labeled primer. Gels were dried and analyzed using a PhosphorImager and the Image-quant software package (Molecular Dynamics). 


\section{Acknowledgments}

We acknowledge support from The Swedish Research Council, Wallenberg Consortium North, the EU-STREP program (FOSRAK), EMBO (to J.V.) and the EU Marie Curie program (to F.D.) for long-term fellowships. Purified Hfq was a generous gift from Eliane Hajnsdorf.

\section{References}

Ali Azam, T., Iwata, A., Nishimura, A., Ueda, S., and Ishihama, A. 1999. Growth phase-dependent variation in protein composition of the Escherichia coli nucleoid. I. Bacteriol. 181: 6361-6370.

Andersen, J., Forst, S.A., Zhao, K., Inouye, M., and Delihas, N. 1989. The function of micF RNA. micF RNA is a major factor in the thermal regulation of OmpF protein in Escherichia coli. J. Biol. Chem. 264: 17961-17970.

Argaman, L., Hershberg, R., Vogel, J., Bejerano, G., Wagner, E.G.H., Margalit, H., and Altuvia, S. 2001. Novel small RNA-encoding genes in the intergenic regions of Escherichia coli. Curr. Biol. 11: 941-950.

Arnold, T.E., Yu, J., and Belasco, J.G. 1998. mRNA stabilization by the ompA 5 ' untranslated region: Two protective elements hinder distinct pathways for mRNA degradation. RNA 4: 319-330.

Belasco, J.G., Nilsson, G., von Gabain, A., and Cohen, S.N. 1986. The stability of $E$. coli gene transcripts is dependent on determinants localized to specific mRNA segments. Cell 46: $245-251$.

Berzal-Herranz, A., Wagner, E.G.H., and Diaz-Orejas, R. 1991. Control of replication of plasmid R1: The intergenic region between copA and repA modulates the level of expression of repA. Mol. Microbiol. 5: 97-108.

Blomberg, P., Wagner, E.G.H., and Nordström, K. 1990. Control of replication of plasmid R1: The duplex between the antisense RNA, CopA, and its target, CopT, is processed specifically in vivo and in vitro by RNase III. EMBO J. 9: 23312340.

Casadaban, M.J., Chou, J., and Cohen, S.N. 1980. In vitro gene fusions that join an enzymatically active $\beta$-galactosidase segment to amino-terminal fragments of exogenous proteins: Escherichia coli plasmid vectors for the detection and cloning of translational initiation signals. J. Bacteriol. 143: 971980.

Chen, L.H., Emory, S.A., Bricker, A.L., Bouvet, P., and Belasco, J.G. 1991. Structure and function of a bacterial mRNA stabilizer: Analysis of the $5^{\prime}$ untranslated region of ompA mRNA. J. Bacteriol. 173: 4578-4586.

Chen, S., Lesnik, E.A., Hall, T.A., Sampath, R., Griffey, R.H., Ecker, D.J., and Blyn, L.B. 2002. A bioinformatics based approach to discover small RNA genes in the Escherichia coli genome. Biosystems 65: 157-177.

Chen, S., Zhang, A., Blyn, L.B., and Storz, G. 2004. MicC, a second small-RNA regulator of Omp protein expression in Escherichia coli. J. Bacteriol. 186: 6689-6697.

Church, G.M. and Gilbert, W. 1984. Genomic sequencing. Proc. Nat1. Acad. Sci. 81: 1991-1995.

Delihas, N. and Forst, S. 2001. MicF: An antisense RNA gene involved in response of Escherichia coli to global stress factors. J. Mol. Biol. 313: 1-12.

Geissmann, T.A. and Touati, D. 2004. Hfq, a new chaperoning role: Binding to messenger RNA determines access for small RNA regulator. $E M B O$ T. 23: 396-405.

Gibert, I. and Barbe, J. 1990. Cyclic AMP stimulates transcription of the structural gene of the outer-membrane protein
OmpA of Escherichia coli. FEMS Microbiol. Lett. 56: 307311.

Gottesman, S. 2004. The small RNA regulators of Escherichia coli: Roles and mechanisms. Annu. Rev. Microbiol. 58: 303 328.

Hartz, D., McPheeters, D.S., Traut, R., and Gold, L. 1988. Extension inhibition analysis of translation initiation complexes. Methods Enzymol. 164: 419-425.

Hjalt, T.A. and Wagner, E.G.H. 1995. Bulged-out nucleotides protect an antisense RNA from RNase III cleavage. Nucleic Acids Res. 23: 571-579.

Huntzinger, E., Boisset, S., Saveanu, C., Benito, Y., Geissmann, T., Namane, A., Lina, G., Etienne, J., Ehresmann, B., Ehresmann, C., et al. 2005. Staphylococcus aureus RNAIII and the endoribonuclease III coordinately regulate spa gene expression. EMBO J. 24: 824-835.

Kajitani, M., Kato, A., Wada, A., Inokuchi, Y., and Ishihama, A. 1994. Regulation of the Escherichia coli hfq gene encoding the host factor for phage Q $\beta$. J. Bacteriol. 176: 531-534.

Lease, R.A. and Woodson, S.A. 2004. Cycling of the Sm-like protein Hfq on the DsrA small regulatory RNA. J. Mol. Biol. 344: 1211-1223.

Lugtenberg, B., Peters, R., Bernheimer, H., and Berendsen, W. 1976. Influence of cultural conditions and mutations on the composition of the outer membrane proteins of Escherichia coli. Mol. Gen. Genet. 147: 251-262.

Lutz, R. and Bujard, H. 1997. Independent and tight regulation of transcriptional units in Escherichia coli via the LacR/O, the TetR/O and AraC/I1-I2 regulatory elements. Nucleic Acids Res. 25: 1203-1210.

Matsuyama, S., Inokuchi, K., and Mizushima, S. 1984. Promoter exchange between ompF and ompC, genes for osmoregulated major outer membrane proteins of Escherichia coli K-12. I. Bacteriol. 158: 1041-1047.

Melefors, O. and von Gabain, A. 1988. Site-specific endonucleolytic cleavages and the regulation of stability of E. coli ompA mRNA. Cell 52: 893-901.

Mikulecky, P.J., Kaw, M.K., Brescia, C.C., Takach, J.C., Sledjeski, D.D., and Feig, A.L. 2004. Escherichia coli Hfq has distinct interaction surfaces for DsrA, rpoS and poly(A) RNAs. Nat. Struct. Mol. Biol. 11: 1206-1214.

Moll, I., Afonyushkin, T., Vytvytska, O., Kaberdin, V.R., and Bläsi, U. 2003a. Coincident Hfq binding and RNase E cleavage sites on mRNA and small regulatory RNAs. RNA 9: 1308-1314.

Moll, I., Leitsch, D., Steinhauser, T., and Bläsi, U. 2003b. RNA chaperone activity of the Sm-like Hfq protein. EMBO Rep. 4: 284-289.

Møller, T., Franch, T., Hojrup, P., Keene, D.R., Bachinger, H.P., Brennan, R.G., and Valentin-Hansen, P. 2002. Hfq: A bacterial Sm-like protein that mediates RNA-RNA interaction. Mol. Cell 9: 23-30.

Morfeldt, E., Taylor, D., von Gabain, A., and Arvidson, S. 1995. Activation of $\alpha$-toxin translation in Staphylococcus aureus by the trans-encoded antisense RNA, RNAIII. EMBO I. 14: 4569-4577.

Nilsson, G., Belasco, J.G., Cohen, S.N., and von Gabain, A. 1984. Growth-rate dependent regulation of mRNA stability in Escherichia coli. Nature 312: 75-77.

Persson, C., Wagner, E.G.H., and Nordström, K. 1988. Control of replication of plasmid R1: Kinetics of in vitro interaction between the antisense RNA, CopA, and its target, CopT. EMBO I. 7: 3279-3288.

Repoila, F., Majdalani, N., and Gottesman, S. 2003. Small noncoding RNAs, coordinators of adaptation processes in Escherichia coli: The RpoS paradigm. Mol. Microbiol. 48: 855-861. 


\section{Udekwu et al.}

Riede, I., Degen, M., and Henning, U. 1985. The receptor specificity of bacteriophages can be determined by a tail fiber modifying protein. EMBO J. 4: 2343-2346.

Rivas, E., Klein, R.J., Jones, T.A., and Eddy, S.R. 2001. Computational identification of noncoding RNAs in E. coli by comparative genomics. Curr. Biol. 11: 1369-1373.

Storz, G., Opdyke, J.A., and Zhang, A. 2004. Controlling mRNA stability and translation with small, noncoding RNAs. Curr. Opin. Microbiol. 7: 140-144.

Sugawara, E. and Nikaido, H. 1992. Pore-forming activity of OmpA protein of Escherichia coli. J. Biol. Chem. 267: 25072511.

Valentin-Hansen, P., Eriksen, M., and Udesen, C. 2004. The bacterial Sm-like protein Hfq: A key player in RNA transactions. Mol. Microbiol. 51: 1525-1533.

Vogel, J., Bartels, V., Tang, T.H., Churakov, G., Slagter-Jäger, J.G., Hüttenhofer, A., and Wagner, E.G.H. 2003. RNomics in Escherichia coli detects new sRNA species and indicates parallel transcriptional output in bacteria. Nucleic Acids Res. 31: 6435-6443.

Vogel, J., Argaman, L., Wagner, E.G.H., and Altuvia, S. 2004. The small RNA IstR inhibits synthesis of an SOS-induced toxic peptide. Curr. Biol. 14: 2271-2276.

Vytvytska, O., Jakobsen, J.S., Balcunaite, G., Andersen, J.S., Baccarini, M., and von Gabain, A. 1998. Host factor I, Hfq, binds to Escherichia coli ompA mRNA in a growth rate-dependent fashion and regulates its stability. Proc. Natl. Acad. Sci. 95: $14118-14123$.

Vytvytska, O., Moll, I., Kaberdin, V.R., von Gabain, A., and Bläsi, U. 2000. Hfq (HF1) stimulates ompA mRNA decay by interfering with ribosome binding. Genes \& Dev. 14: 11091118.

Wagner, E.G.H. and Vogel, J. 2003. Noncoding RNAs encoded by bacterial chromosomes. In Noncoding RNAs (eds. J. Barciszewski and V. Erdmann), pp. 243-259. Landes Bioscience, Austin, TX.

Wagner, E.G.H., Altuvia, S., and Romby, P. 2002. Antisense RNAs in bacteria and their genetic elements. Adv. Genet. 46: 361-398.

Wang, Y. and Kim, K.S. 2002. Role of OmpA and IbeB in Escherichia coli $\mathrm{K} 1$ invasion of brain microvascular endothelial cells in vitro and in vivo. Pediatr. Res. 51: 559-563.

Wassarman, K.M., Repoila, F., Rosenow, C., Storz, G., and Gottesman, S. 2001. Identification of novel small RNAs using comparative genomics and microarrays. Genes \& Dev. 15: $1637-1651$.

Zhang, A., Wassarman, K.M., Ortega, J., Steven, A.C., and Storz, G. 2002. The Sm-like Hfq protein increases OxyS RNA interaction with target mRNAs. Mol. Cell 9: 11-22.

Zhang, A., Wassarman, K.M., Rosenow, C., Tjaden, B.C., Storz, G., and Gottesman, S. 2003. Global analysis of small RNA and mRNA targets of Hfq. Mol. Microbiol. 50: 1111-1124.

Zuker, M. 2003. Mfold Web server for nucleic acid folding and hybridization prediction. Nucleic Acids Res. 31: 3406-3415. 


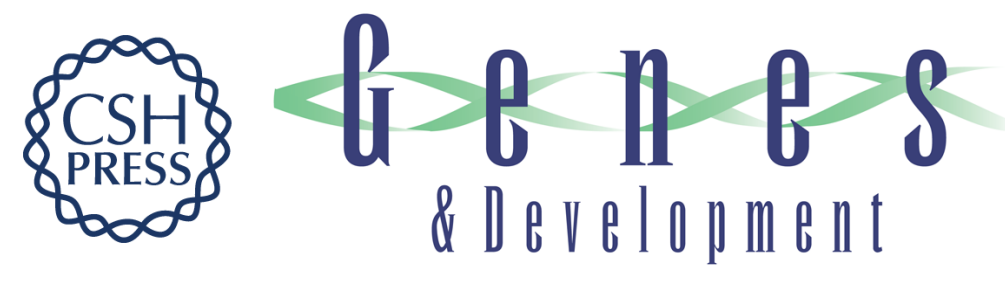

\section{Hfq-dependent regulation of OmpA synthesis is mediated by an antisense RNA}

Klas I. Udekwu, Fabien Darfeuille, Jörg Vogel, et al.

Genes Dev. 2005, 19:

Access the most recent version at doi:10.1101/gad.354405

Supplemental
Material http://genesdev.cshlp.org/content/suppl/2005/09/20/19.19.2355.DC1

References This article cites 48 articles, 15 of which can be accessed free at: http://genesdev.cshlp.org/content/19/19/2355.full.html\#ref-list-1

License

Email Alerting

Service

Receive free email alerts when new articles cite this article - sign up in the box at the top right corner of the article or click here.

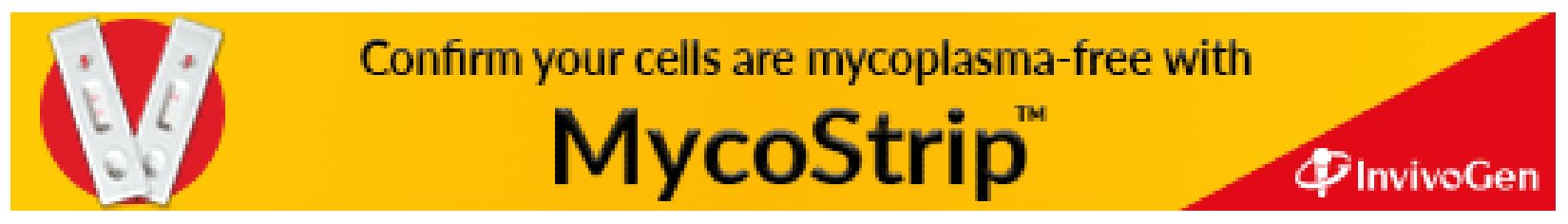

